\title{
Analisa JST Untuk Memprediksi Pembuatan SIM Menggunakan Metode Algoritma Backpropagation
}

\author{
Mirza Rahul, Indra Gunawan, Fitri Anggraini, Sumarno, Ika Okta Kirana \\ Program Studi Teknik Informatika, STIKOM Tunas Bangsa, Pematangsiantar, Indonesia \\ Email: 1'mirza1501093@gmail.com, ${ }^{2}$ indra@amiktunasbangsa.ac.id, ${ }^{3}$ fitrianggraini@amiktunasbangsa.ac.id \\ ${ }^{4}$ sumarno@amiktunasbangsa.ac.id , 5ikaoktakirana@amiktunasbangsa.ac.id
}

\begin{abstract}
Abstrak-Pada suatu perusahaan pelayanan jasa terdapat pelanggan yang menjadi konsumen perusahaan tersebut. Kepuasan pelanggan terbentuk dari tingkat kinerja dan loyalitas perusahaan. Apabila perusahaan tidak mengetahui tentang tingkat kepuasan pelanggan maka perusahaan juga tidak dapat mengembangkan pelayanan mereka. Maka dari itu Satpas Polres Pematangsiantar perlu mengetahui tingkat kepuasan pelanggan demi meningkatkan kinerja dan loyalitas mereka. Maka diperlukan penelitian untuk mengetahui tingkat kepuasan pelanggan melalui metode Jaringan Syaraf Tiruan dengan algoritma backpropagation yang selanjutnya diprediksi dan dicari hasil yang terbaik yang akan digunakan untuk memberikan hasil yang terbaik dan akan menampilkan hasil dari masalah yang dihadapi.
\end{abstract}

Kata Kunci: Jaringan Syaraf Tiruan, Prediksi, Backpropagation, Matlab

Abstract-In a service company there are customers who become consumers of the company. Customer satisfaction is formed from the level of performance and company loyalty. If the company does not know about the level of customer satisfaction, the company also cannot develop their services. So from that Pematangsiantar Police Satpas need to know the level of customer satisfaction in order to improve their performance and loyalty. So research is needed to determine the level of customer satisfaction through the Artificial Neural Network method with the backpropagation algorithm which is then predicted and the best results will be searched to be used to give the best results and will display the results of the problems encountered.

Keywords: Artificial Neural Networks, Prediction, Backpropagation, Matlab

\section{PENDAHULUAN}

Di Indonesia, Surat Izin Mengemudi ( SIM ) adalah bukti registrasi dan indentifikasi yang diberikan oleh Polri kepada seseorang yang telah memenuhi persyaratan administrasi, sehat jasmani dan rohani, memahami peraturan lalu lintas dan terampil mengemudikan kendaraan bermotor. Setiap orang yang mengemudikan kendaraan bermotor di jalan wajib memiliki Surat Izin Mengemudi sesuai dengan jenis kendaraan bermotor yang dikemudikan ( Pasal 77 ayat (1) UU No, 22 Tahun 2009 ). Untuk mempermudah kinerja Sat Lantas khususnya dibagian SATPAS ( Satuan Penyelenggara Administrasi SIM ) di Polres Pematangsiantar,penulis melalukan penilitan berupa memprediksi apa saja yang perlu di perbaiki dalam sistem kerja pegawai menggunakan Jaringan Syaraf Tiruan backpropagation.

Metode Jaringan Syaraf Tiruan backpropagationmerupakan metode yang banyak digunakan untuk diaplikasikan pada penyelesaian suatu masalah berkaitan dengan identifikasi, prediksi dan pengenalan pola. Penelitian yang menggunakan metode backpropagation, salah satunya untuk memprediksi pembuatan SIM yang ada di Satpas Polres Pematangsiantar. Metode backpropagation sendiri dipilih karena merupakan salah satu metode pembelajaran yang cocok digunan untuk menangani nilai yang berada di dataset. Algoritma ini akan menghasilkan kinerja yang lebih baik karena dapat mewujudkan sistem konsisten bekerja dengan baik.

\section{METODE PENELITIAN}

\subsection{Metode Pengumpulan Data}

Teknik atau cara yang dilakukan oleh penulis untuk mengumpulkan data. Pengumpulan data dilakukan untuk memperoleh indormasi yang dibutuhkan dalam rangka mencapai tujuan penelitian. Dalam melakukan penelitian ini, sumber pengumpulan data yang diambil dari Satpas Polres Pematangsiantar mulai dari tahun 2015, 2016 2017 hingga 2018.

\subsection{Analisa Dataset}

Dataset yang digunakan pada penelitian ini adalah dataset banyaknya pembuatan SIM 2015 sampai dengan 2018.Penelitian ini menggunakan dataset tahun 2015 dan 2018 sebagai data training. Kemudian datasetditahun tersebut dijadikan data testing untuk memprediksi barang ditahun 2019. Berikut ini dataset yang didapatkan dari hasil penelitian, dapat diliat pada tabel sebagai berikut: 
Available Online at https://ejurnal.stmik-budidarma.ac.id/index.php/mib DOI 10.30865/mib.v4i1.1742

Tabel 1. Jenis jenis database

\begin{tabular}{ccccc}
\hline No & Bulan & 2015 & 2016 & 2017 \\
\hline 01 & Januari & 1540 & 2188 & 1289 \\
02 & Februari & 1154 & 1564 & 1007 \\
03 & Maret & 1254 & 1620 & 1134 \\
04 & April & 1100 & 1753 & 986 \\
05 & Mei & 1363 & 1967 & 1278 \\
06 & Juni & 1019 & 1301 & 1085 \\
07 & Juli & 1756 & 1356 & 1456 \\
08 & Agustus & 1343 & 1262 & 1421 \\
09 & September & 1095 & 1230 & 1151 \\
10 & Oktober & 1476 & 1363 & 1275 \\
11 & November & 1946 & 1414 & 1801 \\
12 & Desember & 1397 & 1232 & 1230 \\
\hline
\end{tabular}

\section{HASIL DAN PEMBAHASAN}

Analisa dan Pembahasan dalam skripsi ini berupa pengerjaan menormalisasi data, pelatihan dan pengujian dengan program Matlab serta hasil dalam memprediksi banyaknya masyarakat dalam pembuatan SIM di Satpas Pematangsiantar dengan menggunakan metode backpropogation. Hasil dari penelitian dan implementasi yang dilakukan adalah sebagai berikut:

Normalisasi bertujuan untuk mempermudah dalam melakukan pengolahan data menggunakan software Matlab. Normalisasi menggunakan formula berikut:

$$
x^{\prime}=\frac{0,8(x-a)}{(b-a)}+0,1
$$

Keterangan:

$\mathrm{x}^{\prime} \quad$ : Data Transformasi

$\mathrm{x} \quad$ : Data yang akan ditransformasi

a : Data minimum rata-rata

b : Data Maximum rata-rata

\subsection{Pelatihan dan Pengujian Data}

Pada penelitian ini menggunakan sebanyak 5 (lima) arsitektur pelatihan dan pengujian data yakni 12-3-1, 12-5-1, 12-8-1, 12-10-1, 12-11-1. Layer masukan menggunakan 12 Neuron, layer tersembunyi 2 neuron serta 1 neuron keluaran.Source code pelatihan backpropagation yang digunakan dengan aplikasi Matlab $R 2011 b$

Tabel 2. Data Awal Pelatihan (Training) Sebelum di Normalisasi

\begin{tabular}{|c|c|c|c|c|c|c|c|c|c|c|c|c|}
\hline Januari & Februari & Maret & April & Mei & Juni & Juli & Agustus & September & Oktober & November & Desember & Target \\
\hline 1540 & 1154 & 1254 & 1100 & 1363 & 1019 & 1756 & 1343 & 1095 & 1476 & 1946 & 1397 & 2188 \\
\hline 1154 & 1254 & 1100 & 1363 & 1019 & 1756 & 1343 & 1095 & 1476 & 1946 & 1397 & 2188 & 1564 \\
\hline 1254 & 1100 & 1363 & 1019 & 1756 & 1343 & 1095 & 1476 & 1946 & 1397 & 2188 & 1564 & 1620 \\
\hline 1100 & 1363 & 1019 & 1756 & 1343 & 1095 & 1476 & 1946 & 1397 & 2188 & 1564 & 1620 & 1753 \\
\hline 1363 & 1019 & 1756 & 1343 & 1095 & 1476 & 1946 & 1397 & 2188 & 1564 & 1620 & 1753 & 1967 \\
\hline 1019 & 1756 & 1343 & 1095 & 1476 & 1946 & 1397 & 2188 & 1564 & 1620 & 1753 & 1967 & 1301 \\
\hline 1756 & 1343 & 1095 & 1476 & 1946 & 1397 & 2188 & 1564 & 1620 & 1753 & 1967 & 1301 & 1356 \\
\hline 1343 & 1095 & 1476 & 1946 & 1397 & 2188 & 1564 & 1620 & 1753 & 1967 & 1301 & 1356 & 1262 \\
\hline 1095 & 1476 & 1946 & 1397 & 2188 & 1564 & 1620 & 1753 & 1967 & 1301 & 1356 & 1262 & 1230 \\
\hline 1476 & 1946 & 1397 & 2188 & 1564 & 1620 & 1753 & 1967 & 1301 & 1356 & 1262 & 1230 & 1363 \\
\hline 1946 & 1397 & 2188 & 1564 & 1620 & 1753 & 1967 & 1301 & 1356 & 1262 & 1230 & 1363 & 1414 \\
\hline 1397 & 2188 & 1564 & 1620 & 1753 & 1967 & 1301 & 1356 & 1262 & 1230 & 1363 & 1414 & 1232 \\
\hline
\end{tabular}

Data pada tabel 2 adalah data training yang akan dinormalisasi yakni data pada tahun 2015 dan sebagai target adalah pada tahun 2016

Tabel 3. Data Training Sesudah di Normalisasi

\begin{tabular}{rrrrrccrrrrrrr}
\hline Januari & Februari & Maret & April & Mei & Juni & Juli & Agustus & September & Oktober & November & Desember & Target \\
\hline 0,4565 & 0,1924 & 0,2608 & 0,1554 & 0,3354 & 0,1000 & 0,6044 & 0,3217 & 0,1520 & 0,4127 & 0,7344 & 0,3587 & 0,9000 \\
0,1924 & 0,2608 & 0,1554 & 0,3354 & 0,1000 & 0,6044 & 0,3217 & 0,1520 & 0,4127 & 0,7344 & 0,3587 & 0,9000 & 0,4730 \\
0,2608 & 0,1554 & 0,3354 & 0,1000 & 0,6044 & 0,3217 & 0,1520 & 0,4127 & 0,7344 & 0,3587 & 0,9000 & 0,4730 & 0,5113 \\
0,1554 & 0,3354 & 0,1000 & 0,6044 & 0,3217 & 0,1520 & 0,4127 & 0,7344 & 0,3587 & 0,9000 & 0,4730 & 0,5113 & 0,6023 \\
0,3354 & 0,1000 & 0,6044 & 0,3217 & 0,1520 & 0,4127 & 0,7344 & 0,3587 & 0,9000 & 0,4730 & 0,5113 & 0,6023 & 0,7488 \\
0,1000 & 0,6044 & 0,3217 & 0,1520 & 0,4127 & 0,7344 & 0,3587 & 0,9000 & 0,4730 & 0,5113 & 0,6023 & 0,7488 & 0,2930 \\
0,6044 & 0,3217 & 0,1520 & 0,4127 & 0,7344 & 0,3587 & 0,9000 & 0,4730 & 0,5113 & 0,6023 & 0,7488 & 0,2930 & 0,3306
\end{tabular}


JURNAL MEDIA INFORMATIKA BUDIDARMA

Volume 4, Nomor 1, Januari 2020, Page 124-128

ISSN 2614-5278 (media cetak), ISSN 2548-8368 (media online)

Available Online at https://ejurnal.stmik-budidarma.ac.id/index.php/mib DOI $10.30865 /$ mib.v4i1.1742

\begin{tabular}{|c|c|c|c|c|c|c|c|c|c|c|c|c|}
\hline 0,3217 & 0,1520 & 0,4127 & 0,7344 & 0,3587 & 0,9000 & 0,4730 & 0,5113 & 0,6023 & 0,7488 & 0,2930 & 0,3306 & 0,2663 \\
\hline 0,1520 & 0,4127 & 0,7344 & 0,3587 & 0,9000 & 0,4730 & 0,5113 & 0,6023 & 0,7488 & 0,2930 & 0,3306 & 0,2663 & 0,2444 \\
\hline 0,4127 & 0,7344 & 0,3587 & 0,9000 & 0,4730 & 0,5113 & 0,6023 & 0,7488 & 0,2930 & 0,3306 & 0,2663 & 0,2444 & 0,3354 \\
\hline 0,7344 & 0,3587 & 0,9000 & 0,4730 & 0,5113 & 0,6023 & 0,7488 & 0,2930 & 0,3306 & 0,2663 & 0,2444 & 0,3354 & 0,3703 \\
\hline 0,3587 & 0,9000 & 0,4730 & 0,5113 & 0,6023 & 0,7488 & 0,2930 & 0,3306 & 0,2663 & 0,2444 & 0,3354 & 0,3703 & 0,2458 \\
\hline
\end{tabular}

Berikut contoh perhitungan normalisasi:

$\mathrm{X}^{\prime}=\frac{0,8(1540-1540)}{2188-1019}+0,1$

$X^{\prime}=\frac{0,8(1154-1540)}{2188-1019}+0,1$

Tabel 4. Data Awal Pelatihan (Pelatihan) Sebelum di Normalisasi

\begin{tabular}{|c|c|c|c|c|c|c|c|c|c|c|c|c|}
\hline Januari & Februari & Maret & April & Mei & Juni & Juli & Agustus & September & Oktober & November & Desember & Target \\
\hline 1289 & 1007 & 1134 & 986 & 1278 & 1085 & 1456 & 1421 & 1151 & 1275 & 1801 & 1230 & 1567 \\
\hline 1007 & 1134 & 986 & 1278 & 1085 & 1456 & 1421 & 1151 & 1275 & 1801 & 1230 & 1567 & 1413 \\
\hline 1134 & 986 & 1278 & 1085 & 1456 & 1421 & 1151 & 1275 & 1801 & 1230 & 1567 & 1413 & 1320 \\
\hline 986 & 1278 & 1085 & 1456 & 1421 & 1151 & 1275 & 1801 & 1230 & 1567 & 1413 & 1320 & 1151 \\
\hline 1278 & 1085 & 1456 & 1421 & 1151 & 1275 & 1801 & 1230 & 1567 & 1413 & 1320 & 1151 & 1143 \\
\hline 1085 & 1456 & 1421 & 1151 & 1275 & 1801 & 1230 & 1567 & 1413 & 1320 & 1151 & 1143 & 1301 \\
\hline 1456 & 1421 & 1151 & 1275 & 1801 & 1230 & 1567 & 1413 & 1320 & 1151 & 1143 & 1301 & 1265 \\
\hline 1421 & 1151 & 1275 & 1801 & 1230 & 1567 & 1413 & 1320 & 1151 & 1143 & 1301 & 1265 & 1121 \\
\hline 1151 & 1275 & 1801 & 1230 & 1567 & 1413 & 1320 & 1151 & 1143 & 1301 & 1265 & 1121 & 1350 \\
\hline 1275 & 1801 & 1230 & 1567 & 1413 & 1320 & 1151 & 1143 & 1301 & 1265 & 1121 & 1350 & 1176 \\
\hline 1801 & 1230 & 1567 & 1413 & 1320 & 1151 & 1143 & 1301 & 1265 & 1121 & 1350 & 1176 & 1485 \\
\hline 1230 & 1567 & 1413 & 1320 & 1151 & 1143 & 1301 & 1265 & 1121 & 1350 & 1176 & 1485 & 1530 \\
\hline
\end{tabular}

Data pada tabel 4 adalah data training yang akan dinormalisasi yakni data pada tahun 2017 dan sebagai target adalah data pada tahun 2018 .

Tabel 5. Data Training Sesudah di Normalisasi

\begin{tabular}{cccccccccrrrr}
\hline Januari & Februari & Maret & April & Mei & Juni & Juli & Agustus & September & Oktober & November & Desember & Target \\
\hline 0,4565 & 0,1924 & 0,2608 & 0,1554 & 0,3354 & 0,1000 & 0,6044 & 0,3217 & 0,1520 & 0,4127 & 0,7344 & 0,3587 & 0,9000 \\
0,1924 & 0,2608 & 0,1554 & 0,3354 & 0,1000 & 0,6044 & 0,3217 & 0,1520 & 0,4127 & 0,7344 & 0,3587 & 0,9000 & 0,4730 \\
0,2608 & 0,1554 & 0,3354 & 0,1000 & 0,6044 & 0,3217 & 0,1520 & 0,4127 & 0,7344 & 0,3587 & 0,9000 & 0,4730 & 0,5113 \\
0,1554 & 0,3354 & 0,1000 & 0,6044 & 0,3217 & 0,1520 & 0,4127 & 0,7344 & 0,3587 & 0,9000 & 0,4730 & 0,5113 & 0,6023 \\
0,3354 & 0,1000 & 0,6044 & 0,3217 & 0,1520 & 0,4127 & 0,7344 & 0,3587 & 0,9000 & 0,4730 & 0,5113 & 0,6023 & 0,7488 \\
0,1000 & 0,6044 & 0,3217 & 0,1520 & 0,4127 & 0,7344 & 0,3587 & 0,9000 & 0,4730 & 0,5113 & 0,6023 & 0,7488 & 0,2930 \\
0,6044 & 0,3217 & 0,1520 & 0,4127 & 0,7344 & 0,3587 & 0,9000 & 0,4730 & 0,5113 & 0,6023 & 0,7488 & 0,2930 & 0,3306 \\
0,3217 & 0,1520 & 0,4127 & 0,7344 & 0,3587 & 0,9000 & 0,4730 & 0,5113 & 0,6023 & 0,7488 & 0,2930 & 0,3306 & 0,2663 \\
0,1520 & 0,4127 & 0,7344 & 0,3587 & 0,9000 & 0,4730 & 0,5113 & 0,6023 & 0,7488 & 0,2930 & 0,3306 & 0,2663 & 0,2444 \\
0,4127 & 0,7344 & 0,3587 & 0,9000 & 0,4730 & 0,5113 & 0,6023 & 0,7488 & 0,2930 & 0,3306 & 0,2663 & 0,2444 & 0,3354 \\
0,7344 & 0,3587 & 0,9000 & 0,4730 & 0,5113 & 0,6023 & 0,7488 & 0,2930 & 0,3306 & 0,2663 & 0,2444 & 0,3354 & 0,3703 \\
0,3587 & 0,9000 & 0,4730 & 0,5113 & 0,6023 & 0,7488 & 0,2930 & 0,3306 & 0,2663 & 0,2444 & 0,3354 & 0,3703 & 0,2458 \\
\hline
\end{tabular}

Berikut contoh perhitungan normalisasi:

$\mathrm{X}^{\prime}=\frac{0,8(1289-1289)}{1801-986}+0,1$

$\mathrm{X}^{\prime}=\frac{0,8(1007-1145)}{1801-986}+0,1$

\subsection{Kesimpulan Jaringan Syaraf Tiruan}

Tabel 6. Tabel Hasil Kesimpulan Pelatihan dan Pengujian Jaringan

\begin{tabular}{ccccccc}
\hline No & Arsitektur & Epoch & Waktu & MSE Training & MSE Testing & Akurasi \\
\hline 1 & $12-3-1$ & 26352 & $00: 50$ & 0,01791138 & 0,04068227 & $\mathbf{9 2 \%}$ \\
2 & $12-5-1$ & 23930 & $01: 15$ & 0,01826396 & 0,05483166 & $\mathbf{6 7 \%}$ \\
3 & $12-8-1$ & 23196 & $00: 21$ & 0,01834114 & 0,07748571 & $\mathbf{7 5 \%}$ \\
4 & $12-10-1$ & 6274 & $00: 07$ & 0,01691660 & 0,07492021 & $\mathbf{5 0 \%}$ \\
5 & $12-11-1$ & 14675 & $00: 11$ & 0,01820312 & 0,06460630 & $\mathbf{7 5 \%}$ \\
\hline
\end{tabular}

Pada tabel 6 arsitektur yang digunakan untuk pelatihan sebanyak 5 arsitektur. Pada 5 arsitektur ini menggunakan Learning rate 0,1 target error (goal) 0,01 dan maksimum epoch nya adalah 100000 iterasi serta untuk menghasilkan error paling rendah menggunakan traingd. Penelitian ini menyimpulkan bahwa arsitektur 12-3-1 dengan akurasi sebesar 92\%, epochs 26352 iterasi, waktu 00:50 merupakan arsitektur terbaik yang akan digunakan untuk melakukan prediksi tahun-tahun berikutnya 
Available Online at https://ejurnal.stmik-budidarma.ac.id/index.php/mib DOI $10.30865 /$ mib.v4i1.1742

\subsection{Implementasi}

Estimasi menggunakan arsitektur terbaik 12-3-1. Maksudnya, layer masukan menggunakan 12 neuron, layer tersembunyi 2 neuron serta 1 neuron layer keluaran. Proses prediksi dapat dilihat pada tabel 7 berikut:

Tabel 7. Prediksi Data Tahun 2019

\begin{tabular}{ccccc}
\hline Bulan & Data Real & Target & Target Prediksi & Prediksi \\
\hline Januari & 1567 & 0,6703 & 0,4352 & 1308 \\
Februari & 1413 & 0,5191 & 0,5502 & 1372 \\
Maret & 1320 & 0,4279 & 0,3415 & 1256 \\
April & 1151 & 0,2620 & 0,3169 & 1242 \\
Mei & 1143 & 0,2541 & 0,3137 & 1240 \\
Juni & 1301 & 0,4092 & 0,3967 & 1286 \\
Juli & 1265 & 0,3739 & 0,3767 & 1275 \\
Agustus & 1121 & 0,2325 & 0,3612 & 1267 \\
September & 1350 & 0,4573 & 0,3705 & 1272 \\
Oktober & 1176 & 0,2865 & 0,4285 & 1304 \\
November & 1485 & 0,5898 & 0,6430 & 1424 \\
Desember & 1530 & 0,6340 & 0,5840 & 1391 \\
\hline
\end{tabular}

Tabel 8. Prediksi Data Tahun 2020

\begin{tabular}{ccccc}
\hline Bulan & Data Real & Target & Target Prediksi & Prediksi \\
\hline Januari & 1308 & 0,4354 & 0,4182 & 1313 \\
Februari & 1372 & 0,5502 & 0,3879 & 1306 \\
Maret & 1256 & 0,3422 & 0,4618 & 1323 \\
April & 1242 & 0,3170 & 0,3488 & 1297 \\
Mei & 1240 & 0,3135 & 0,4909 & 1330 \\
Juni & 1286 & 0,3960 & 0,3625 & 1300 \\
Juli & 1275 & 0,3762 & 0,4640 & 1324 \\
Agustus & 1267 & 0,3619 & 0,4115 & 1312 \\
September & 1272 & 0,3709 & 0,3910 & 1307 \\
Oktober & 1304 & 0,4283 & 0,3699 & 1302 \\
November & 1424 & 0,6435 & 0,4699 & 1325 \\
Desember & 1391 & 0,5843 & 0,6203 & 1360 \\
\hline
\end{tabular}

Tabel 9. Prediksi Data Tahun 2021

\begin{tabular}{ccccc}
\hline Bulan & Data Real & Target & Target Prediksi & Prediksi \\
\hline Januari & 1313 & 0,4174 & 0,3237 & 1315 \\
Februari & 1306 & 0,3870 & 0,3050 & 1313 \\
Maret & 1323 & 0,4609 & 0,3157 & 1314 \\
April & 1297 & 0,3478 & 0,3999 & 1321 \\
Mei & 1330 & 0,4913 & 0,4693 & 1326 \\
Juni & 1300 & 0,3609 & 0,3905 & 1320 \\
Juli & 1324 & 0,4652 & 0,3802 & 1319 \\
Agustus & 1312 & 0,4130 & 0,4238 & 1322 \\
September & 1307 & 0,3913 & 0,2417 & 1308 \\
Oktober & 1302 & 0,3696 & 0,2999 & 1313 \\
November & 1325 & 0,4696 & 0,4360 & 1323 \\
Desember & 1360 & 0,6217 & 0,4177 & 1322 \\
\hline
\end{tabular}

Data real adalah data yang diperoleh dari hasil prediksi tahun 2019. Data target diperoleh dari data Testing yang sudah di normalisasi. Target prediksi pada tabel diperoleh dari hasil pengujian menggunakan software Matlab $R 2011 b$.Pada tabel 4.18 prediksi ditentukan menggunakan persamaan sebagai berikut:

$$
\text { Prediksi }=\frac{(\text { output }-0,1)(b-a)}{0,8}+a
$$

\section{KESIMPULAN}

Kesimpulan yang dapat diambil setelah melakukan pelatihan dan pengujian data pada jaringan syaraf tiruan dengan menggunakan algoritma backpropagation. Pemodelan terbaik pada penelitian ini adalah 12-3-1 dengan menggunakan learning rate 0.01, MSE pelatihan 0,01791138, MSE pengujian 0,04068227, dan mendapatkan 
Available Online at https://ejurnal.stmik-budidarma.ac.id/index.php/mib DOI 10.30865/mib.v4i1.1742

tingkat akurasi sebesar $92 \%$. Dengan pola 12-3-1 tersebut selanjutnya dilakukan prediksi untuk tahun 20192021 dengan menghasilkan prediksi penjualan yang selalu meningkat dari tahun ke tahun. Untuk tahun 2019 sebanyak 15,637 penjualan, untuk tahun 2020 sebanyak 15,799, dan untuk tahun 2021 sebanyak 15,816.

\section{REFERENCES}

[1] Astria, L., Sitepu, H. R. and Darnius, O. (2013) '1. PENDAHULUAN Polres Tapanuli Selatan merupakan bagian dari Kepolisian Republik In- donesia yang melayani di bidang pemeliharan dan keamanan, ketertiban', Saintia Matematika, 1(5), pp. 435-444.

[2] Goni, J. H. (no date) 'Efektivitas Kinerja Pelayanan Surat Ijin Mengemudi Pada Satuan Lalu Lintas Kepolisian Resor Kota Manado', unsrat, pp. 1-6.

[3] Marjiyono, Bambang Soedijono and Taufiq, E. L. (2018) 'Penggunaan Jaringan Syaraf Tiruan Untuk Meramalkan Permintaan pada Perusahaan Retail', Seminar Nasional Teknologi Informasi dan Multimedia, (2009), pp. 7-12.

[4] Febrina, M., Arina, F. and Ekawati, R. (2013) 'Peramalan Jumlah Permintaan Produksi Menggunakan Metode Jaringan Syaraf Tiruan (JST) Backpropagation', Jurnal Teknik Industri Untirta, 2(1), pp. 174-179.

[5] Wanto, A. and Windarto, A. P. (2017) 'Analisis Prediksi Indeks Harga Konsumen Berdasarkan Kelompok Kesehatan Dengan Menggunakan Metode Backpropagation’, Jurnal \& Penelitian Teknik Informatika Sinkron, 2(2), pp. 37-43. Available at:

[6] Haviluddin (2011) 'Memahami Penggunaan UML (Unified Modelling Language)' Jurnal Informatika Mulawarman' 6(1), pp 1-15.

[7] Budi Cahyono (2013) 'Penggunaan Software Matrix Laboratory (MATLAB) Dalam Pembelajaran Aljabar Linier 'Jurnal PHENOMENON' 1(1) pp 45-62. 